\title{
Tailoring University Counselling Services to Aboriginal and International Students: Lessons from Native and International Student Centres at a Canadian University
}

\author{
Lloyd Hawkeye Robertson \\ Athabasca University \\ Kathryn Holleran \\ Dufferin-Peel Catholic District School Board \\ Marilyn Samuels \\ University of Calgary
}

\begin{abstract}
Critics have suggested that the practice of psychology is based on ethnocentric assumptions that do not necessarily apply to non-European cultures, resulting in the underutilization of counselling centres by minority populations. Few practical, culturally appropriate alternatives have flowed from these concerns. This paper reviews experiences from a doctoral-level practicum in counselling psychology that targeted aboriginal and international university students outside of the mainstream counselling services at a western Canadian university over a two-year period. It recommends an integrated approach, combining assessment, learning strategy skills, and counselling skills while incorporating community development methodology. The paper concludes with recommendations for counsellor training that will enhance services to both international and aboriginal students.
\end{abstract}

\section{Résumé}

Certaines critiques ont suggéré que la pratique de la psychologie est basée sur des hypothèses ethnocentriques qui ne s'appliquent pas nécessairement aux 
cultures non européennes, avec pour résultat que les centres de consultation psychologique sont sous utilisés par les minorités ethniques. En pratique, peu d'alternatives adaptées culturellement ont découlé de ces préoccupations. Ce texte passe en revue l'expérience d'un practicum de niveau de doctorat sur la thérapie psychologique qui visait des étudiants universitaires autochtones ou étrangers à l'extérieur du réseau traditionnel des services de thérapie dans une université de l'ouest canadien sur une période de deux ans. Il recommande une approche intégrée combinant évaluation, compétences en stratégie d'apprentissage, et compétences de conseillers tout en incorporant une méthodologie de développement communautaire. Le texte conclut par des recommandations pour de la formation de thérapeutes qui va améliorer les services aux étudiants autochtones et étrangers.

International and students aboriginal to North America underutilize university counselling services as compared to North American students of European ancestry (Dolan, 1995; Snider, 2001). International students face personal challenges specific to cultural differences, and they often perceive university counselling services to be unsympathetic to their traditions, values, or experiences (Arthur, 2004; Bellini, 2003; Fowler, Glenwright, Bhatia, \& Drapeau, 2011). Some international students come from a history of dispossession and oppression, but others are from families with privileged positions in their home cultures. All may experience cultural dislocation, with accompanying threats to self-validation (Arthur, 2003; Ishiyama, 1995). The foil often used to situate and define these "home" or "traditional" cultures is "western," a term that loosely refers to cultures descended from or associated with $19^{\text {th }}$-century European and U.S. American colonialism, with the added cumulative effects of modernity-largely associated with scientific, technological and commercial change. While the use of this construct is often problematic with respect to clarity of definition and application, it is used here to represent those forces associated with Euro-American civilization perceived as potentially overwhelming to those cultures regarded as "traditional" on the basis of having comparatively longstanding traditions. Thus, the study of psychology as it evolved in the western tradition, having no direct analogue in cultures defined as "traditional," is often viewed as unsupportive of those cultural traditions.

"Western" counselling has also been perceived as not relevant or sympathetic to cultures indigenous to the American continents (McCormick, 1996; Poonwassie \& Charter, 2001; Sojonky, 2010). Aboriginal students come to university with the historical legacy of community-destroying colonialism (Duran \& Duran, 1995; Ray, 1996). During the $20^{\text {th }}$ century in Canada, aboriginal children were commonly isolated from community and family through forced attendance at residential schools (Robertson, 2006; Stout \& Kipling, 2003), with an accompanying increase in social and psychological problems (Brasfield, 2001; Wesley-Esquimaux \& Smolewski, 2004). The resultant legacy of distrust may confound efforts by institutions perceived as colonial to overcome cultural differences.

Indigenization is a process whereby an imported psychology is transformed in ways that are more appropriate to the local culture (Adair, 2006). Minority university students constitute transient populations with fewer on-site cultural supports for identity main- 
tenance as compared to mainstream students. Since professional counselling has been characterized as a western or Euro-American conceptualization (Moody, 1999), we considered it instructive to compare the experience of clients from diverse backgrounds who are culturally non-western, within organizations mandated to deliver targeted support to those populations.

While the process of counselling may have been subsumed in other roles in traditional societies (Korhonen, 2002), the professionalization of counselling that occurred in EuroAmerican cultures resulted in many westerners being culturally prepared to access counsellors and therapists from agencies established for this purpose. The comparative lack of cultural preparedness in traditional societies could inhibit the development of the therapeutic alliance in those minority populations. Since a stable early therapeutic alliance is important for successful outcomes (Hersoug, Hoglend, Havik, \& Monsen, 2010), people unfamiliar with the assumptions of counselling are disadvantaged. By offering services in culturally friendly settings, we were attempting to overcome barriers of unfamiliarity and possible distrust of foreign institutions.

\section{Research Design}

This study is a qualitative description of the experience of offering counselling services at the Native Student Centre and the International Student Centre at a mid-sized Canadian university. Two doctoral students in counselling psychology provided the service, one in each year of the two-year program. The counsellor in the first year of the program was a male Métis in his 50s, and the second-year counsellor was a female Euro-Canadian in her 30s. Both were experienced counsellors prior to their enrolment in the doctoral program, and both were trained in cognitive-behavioural methods, with the first-year counsellor also trained in Adlerian psychotherapy.

Professional supervision was provided by a doctoral psychologist from the university's Disability Resource Centre who was also affiliated with the university's Department of Applied Psychology. Central to the design of the project was the weekly involvement of the Native Student and International Student centres in reviewing the activities of the counsellors and suggesting contextual community issues impacting on the respective populations that could affect individuals and their counselling needs.

The mandate of the Native Student Centre was to provide a culturally appropriate environment supporting aboriginal students by sharing funding and program information, providing assistance in class selection, promoting mutual self-help, and providing cultural events based on First Nations (Amerindian), Métis, and Inuit traditions. The International Student Centre played a similar role of supporting international student achievement by providing workshops on adapting to Canadian cultural norms and expectations, taking English language classes, selecting classes and courses, and accessing funding possibilities. Neither centre had offered professional counselling services prior to accepting a doctoral-level counselling psychologist practicum placement.

At the beginning of each year of the program, the counsellor was introduced to potential clients at meetings of both the Native and International Student centres, and the counsellors offered workshops at both centres on building academic success. Office space was provided at both locations, but the counsellor's two days per week were flexibly allocated, depending on demand. 
Although the regular university counselling service did not keep data on the racial backgrounds of their clients, we were told that they had very few clients from the targeted populations. Regular use of the new service by aboriginal and international students would be an indication of an unmet need that was now, to some extent, being filled; we therefore considered it a measure of success. In addition, both counsellors provided qualitative descriptions of case data for the purpose of comparing and contrasting targeted populations.

\section{Results}

Twenty-three clients (14 native students and nine international students) used the counselling service during its first year of operation, with aboriginal students having almost twice as many sessions per client (5.93) as international students (3.00). The clients included 13 women and 10 men. The average length of each counselling session was 1.33 hours. Lengthy sessions (more than one hour) occurred when students were in crisis; when longer sessions, involving aboriginal storytelling methods, were planned; or when longer sessions were required to complete a psychometric assessment. For example, one international student requested an assessment prior to a disciplinary hearing, and that session took three hours. Table 1 compares international and aboriginal students with respect to their presenting issues.

Nine international students presented with 11 issues for counselling, an average of 1.2 presenting issues per student. The 14 aboriginal students presented with 27 issues, for an average of 1.9 issues per client. The counsellor often did his academic work at the Native Centre office, thus increasing his availability at that centre. In a culture where informal relationships are valued, students frequently made initial contact to "size up" the counsellor before requesting an appointment. Very few aboriginal students booked appointments through the receptionist. No international students were observed "dropping by" for a chat, although international students and the counsellor did engage in informal exchanges in the international student lounge.

While the total number of clients increased slightly to 25, fewer men and more women accessed the service during the project's second year, resulting in a sex ratio of more than 2:1 (17 women, eight men). Further, more international students than aboriginal students accessed the counselling service during its second year. The average length of each counselling session increased slightly to 1.5 hours. Aboriginal students typically presented with one of the following issues: learning strategies, academic interventions, addictions, and anger management. Presenting concerns for international students included communicating with family members in their home country and adjusting to life in Canada. Although both groups of students often initiated counselling with one particular concern (such as study skills), additional issues were often added after two or three sessions. It could be that as these clients experienced positive results involving an initial issue, they gained trust in both the counsellor and the process of counselling, prompting them to present more emotionally laden issues. Counsellor characteristics may influence client receptiveness to the helping experience (Atkinson, Poston, Furlong, \& Mercado, 1989; Bellini, 2003). The slight increase in female and international students during the second year of the project may have been influenced by the gender and race differences between the two therapists. Similar ethnicity appeared to be more important to Amerindian than to Caucasian students, particularly those with a stronger sense of involvement with American Indian culture (Bennett \& BigFoot-Sipes, 1991). 
Table 1

Presenting issues of international and aboriginal students during year one of the counselling service

\begin{tabular}{lccc}
\hline Issue & $\begin{array}{c}\text { International } \\
\text { Students }\end{array}$ & $\begin{array}{c}\text { Aboriginal } \\
\text { Students }\end{array}$ & Totals \\
\hline Relationship issues & 3 & 7 & 10 \\
Academic, learning problems, ADD & 2 & 6 & 8 \\
Sexuality, sexual identity & 2 & 3 & 5 \\
Discrimination, cross-cultural conflict & 1 & 4 & 5 \\
Stress/anxiety & 1 & 3 & 4 \\
Life skills, finding "self” in relation to goals & 2 & 1 & 3 \\
Depression, lack of self-efficacy & 0 & 3 & 3 \\
\hline
\end{tabular}

As in the first year of the project, none of the aboriginal students booked appointments through the receptionist. They would visit the counsellor in person or send her an email requesting an appointment. The counsellor often had lunch in the Native Centre student lounge, which aided in her accessibility to aboriginal students. She was directly and formally introduced to prospective clients in the International Student Centre. Often the student advisor in the International Centre would ask for the counsellor's attendance at an advisory session, allowing the international student to meet the counsellor prior to booking a counselling session. After the initial appointment, all the international students preferred arranging appointment times by sending an email to the counsellor. When the students booked appointments directly with the counsellor, they tended to show up, and the counsellor experienced very few no-shows throughout the course of the year.

The experience of both counsellors was congruent with a hypothesis that some students were unfamiliar or uncomfortable with formal booking procedures involving a receptionist, an intake worker, and eventual assignment to a counsellor, a system used by most counselling agencies. They modified the intake procedure in ways that enhanced their levels of comfort and personalized the process, resulting in increased commitment to engaging with the counsellor.

\section{Qualitative Descriptions of the Aboriginal and International Students Served}

As will be evident in the following examples, many international and aboriginal clients assigned the counsellors roles that were culturally familiar. Further, counselling methods were negotiated with each client and adaptations made to accommodate the client's cultural norms. It was not assumed that practices apparently effective with one client would necessarily translate to another client, even within the same cultural group.

In keeping with their cultural background, some aboriginal clients favoured telling their story in a traditional manner that was non-linear, holistic, and time-consuming. In anticipation of the client-centred benefits of such culturally friendly interaction, the counsellors discarded the "50-minute hour" favoured by most counselling agencies. Clients frequently expressed their appreciation that the service was provided according to 
their own traditions. In one case, the first-year counsellor was offered tobacco-an honour normally afforded traditional elders. Similarly, international students frequently offered thank-you gifts at the end of the counselling sessions.

Despite the need to negotiate and clarify client and counsellor roles and expectations, we also found evidence of cross-cultural similarities. One-third of the international students counselled presented with relationship issues. In one case, it was a long-distance relationship. His fiancée was in an Asian country and now was living and working in different circles than when they had been students together. How could he communicate his insecurities along with his hopes and dreams in ways that she would understand? He could have been a 20-year-old from any culture.

One young woman grappled with distance of another kind. She had fallen in love with a Canadian who was of a different religion. There was no chance that her family would approve. Another young woman discovered on coming to Canada that she was more interested in establishing relationships and self-exploration than in academic studies. She became part of a small community of friends and gave the money that was to go toward her books, lodging, and tuition to help people in that community. A "love triangle" led to the disintegration of friendships upon which that community was based, and the client was left wondering how she was going to pay her father back the money he had invested in her education.

After a successful first semester, a young man from a middle-eastern country decided to party rather than remain studious. He failed or withdrew from all his classes in the next two semesters and was evicted from the student residence after his parties resulted in numerous complaints and one police intervention. He now faced the difficult task of salvaging something from this educational experience before returning home.

Several of the international students who accessed the program during its second year also experienced difficulties with the "new-found freedom" that living in Canada and studying in a less structured environment offered. For instance, several male students from middle-eastern countries had never experienced unstructured time on the Internet. In the new, unmonitored environment, their post-secondary studies suffered because they spent several hours per day gaming and viewing pornographic websites.

The most common issues presented by aboriginal clients during the first year of the project also involved relationships. Clients of both sexes reported partners or spouses who were unsupportive of their education, resulting in problems with childcare and finances. Three clients said visits from unruly family and friends precipitated academic difficulties. For some clients, this represented a conflict between their identity as an aboriginal person and their identity as a student.

Two aboriginal students requested testing for learning disabilities, motivated by the understanding that with such a diagnosis they could receive extra time to write exams and technical support such as computers. Their problem turned out to be not a learning disability but a weakness with the English language. As with many international students, aboriginal students who grew up speaking their native language, or a non-standard form of English, faced extra difficulties when confronted with university-level English.

Clients sometimes alluded to cultural barriers that inhibited them from accessing standard counselling services. One international student said he had thought of seeking therapy for disturbing sexual dreams for more than three years, but he took the concrete 
step to request help only when he saw the service offered at the International Student Centre. An aboriginal student said that he could not have discussed his issues, which involved questioning his culture, with a non-aboriginal counsellor. Another aboriginal student said that she had gone to the campus counselling centre for one session but was unsatisfied due to what she perceived as impersonal service. After having determined that she was "never going back," she happened to pass by the counsellor's office in the Native Centre, introduced herself, and after a brief chat made an appointment. This was the beginning of a satisfying counselling relationship.

Eight of the 23 clients seen during the first year of this program presented with academic or learning difficulties, and this trend continued into the second year of the study. Although this is not surprising, given the academic setting, counselling is often seen as a distinct service, separate from that provided by educational psychologists. Counselling agencies frequently re-refer students with academic concerns to an outside psychometrician for further testing, and the client returns wearing a diagnostic label. Further, clinical psychology is often seen as a separate discipline, from which the client may obtain a separate set of labels. "Diagnostic labels locate the causes of the problem within the individual; this may foreclose consideration of the societal context and interpersonal relations as sources of unhappiness or dysfunction" (Hare-Mustin \& Marecek, 1997 p. 109). The problems inherent in such a fractured approach may be magnified cross-culturally, as became apparent in the following account.

\section{Integrating Holism into Practise: An Illustrative Case}

"Francine" agreed to have her case used illustratively, providing she was given a pseudonym. Nonessential details have been eliminated or changed to further protect confidentiality.

Francine was an aboriginal woman who had been placed in special education classes during grade school. She was diagnosed with a psychiatric illness as a youth, and she made few friends. Shy and withdrawn, she felt alienated from the people in her home reserve community. She completed Grade 12 in an adult upgrading program and enrolled in university because she did not think she was suited for any work that she might enjoy, and she "did not know what else to do."

Francine approached the Disability Resource Centre (DRC) on campus, concerned that she had a learning disability. A native studies class required that she write an essay; since she did not feel competent at that task, she stopped attending. She reported to the DRC, "As a learner, to describe myself, I can only see my difficulties and disappointments." The DRC proposed a collaborative approach that would allow Francine to see herself as a whole or a totality with strengths, as opposed to a fragmented individual defined by her weaknesses, many of which were poorly understood in isolation.

Although this practicum was in counselling psychology, the counsellor had a background in ability testing. The practicum supervisor therefore proposed that the student be guided in dynamic assessment, an approach that demonstrates to clients both their strengths in learning and what they can do to perform better, thus forming a bridge between assessment and counselling. Further, the practicum student also had a background in mental health and was familiar with the condition with which the client had been previously diagnosed. 
In accordance with the client's presenting issue, the treatment plan began with a psycho-educational assessment. During the course of two months, Francine was administered Raven's Progressive Matrices, the Wechsler Adult Intelligence Scale, the Woodcock-Johnson Tests of Achievement, the Nelson-Denny Comprehension subtest, Rey's Complex Figure, the Organizer Test (Feuerstein, Hoffman, \& Rand, 1979), and the Raven's again, used dynamically. The assessment process was not smooth and continuous. Although Francine had not been clinically diagnosed with depression or anxiety, there were times when she presented with sufficient symptoms that she could not continue with planned activities. On such occasions, the counsellor would stop the planned assessment work and deal with the presenting symptoms using cognitive-behavioural techniques. It was thought that failure to suspend assessment at those times would have resulted in an artificially low estimate of ability.

Francine was on antipsychotic medication, and her understanding was that her condition was "a paranoid illness with a chemical imbalance." She heard voices telling her things, sometimes coming from radios. In many aboriginal cultures, such voices are interpreted to be evil spirits or visions (good spirits). Given the content of the voices, Francine concluded they were more like evil spirits and that their voices could be either argued against rationally or ignored. Such externalization is a feature of narrative therapy (White, 1993).

Narrative approaches are also compatible with the aboriginal tradition of storytelling. Francine's story was one of being teased and isolated as a child. Through tears she explained that she was afraid of her own people, even at the university. Counselling included a retelling of that story through the eyes of a newly empowered adult helped by the assessment process. Dynamic assessment includes the teaching of strategies to solve problems, and when Francine demonstrated to herself how quickly she was able to learn a strategy that allowed her to master a set on the Raven's, she was more willing to learn new strategies to cope with her academic and social problems.

Francine exhibited a personal strength in perceptual organization, coupled with weaknesses in making inferential responses. Her pattern of scores in the ability tests, along with her school history, weak reading comprehension, difficulties with executive functioning, and reported difficulties communicating in her native language all supported a hypothesis of a verbal learning disability. A number of recommendations were made to ameliorate the conditions of that disability, including provisions for accommodative support and assistive technology. More importantly, Francine learned that she could be defined by her strengths and that she had the ability to succeed in university.

During the second year of the program, Francine continued to work with the new counsellor on academic strategies and personal concerns using the flexible and adaptable approach modelled during the first year. On several occasions, a pressing personal concern was Francine's main focus, while on other days her attention was centred on her academic studies. Several of the academic-focused sessions addressed specific skills, ranging from formatting papers to editing work to dictionary skills, study skills, and working with abstract concepts. She encountered success in her studies throughout the second year of the program. With perseverance and appropriate support, Francine has now successfully completed her university degree program. 
Specialization carries the risk of fragmentation. Francine had engaged the services of a series of specialists (clinical, counselling, and educational psychologists) prior to this counselling experience, and the resultant fragmentary understanding of her person focused on deficiencies while failing to address central issues of her being. This left her with inadequate skills for understanding and addressing her life situation. Psychology has not always operated so reductionistically. Alfred Adler, for example, viewed the individual to be a "unity" (1967; Thomas \& Marchant, 1993). He held that the therapist, to be effective, must understand the total individual, including his or her cultural context. He also pioneered the practice of multiple therapists working together in an integrated fashion with the same client (Mosak, 1979), and this approach has been extended to narrative therapy (Haley, 2002).

\section{Situating the Client in Community and Historical Contexts}

We have seen how community and historical factors contributed to the set of issues Francine brought to counselling. Two additional aboriginal clients expressed strongly felt negative opinions about aboriginality due to their personal negative experiences involving family and community, which had led the individuals to isolate themselves from their home communities. A fourth client spent successive weekends on her home reserve attempting to help her people in a codependent manner, with a resultant cost to her studies. By combining historical and community development perspectives, these clients were able to attach meaning to their experiences. Two became actively and productively involved in the community surrounding the Native Centre on campus. Another redefined herself as part of a collectivity and placed boundaries on her participation in that collectivity.

In contrast with our aboriginal clients, international students often came from fully functioning communities supportive of their education. Separated from these supportive and directive communities, some international clients engaged in hedonistic, self-destructive behaviours, oblivious to the consequences. We examined how another client attempted to create a substitute but structurally fragile "mini-community" of friends. A middleeastern client reconnected culturally to his family and traditions in a way that aided the process of therapy. He had recurrent nightmares involving the mutilation of women to whom he was attracted, with the result that the man, now in his 30s, had avoided contact with women since he was 19. He had sought the advice of his religious leaders, but resultant prayers and ceremonies proved ineffective. His mother offered to arrange a marriage, but that prospect triggered increased anxiety. He turned to "western counselling" only after it was offered through the International Student Centre. During therapy, he revealed that the nightmares pictured him without eyebrows. Initially, he did not consciously know what eyebrows might symbolize in his culture, but a phone call to his mother resulted in the suggestion that they represented wisdom. A reinterpretation of the dream as representing not him, but a characterization of him without wisdom, provided the breakthrough needed to deal with childhood religious injunctions involving his sexuality.

Deferring to the client's personal expertise also proved valuable in working with aboriginal clients. Traditional Amerindian cultures vary, and individual aboriginal people will likely internalize a mix of cultures, both traditional and modern. The aboriginal clients in this study reported a range of religious views, including Native Spiritual, Christian (both fundamentalist and mainstream), and agnostic. Clients communicated their history and 
worldview to the counsellors, who, in turn, used their expertise in the change process to help develop alternative possibilities. Thus, counselling became a process of collaboration between two experts co-constructing a treatment plan. One aboriginal woman surprised the counsellor by choosing a cognitive-behavioural approach to fight depression. It had been the counsellor's expectation that she would choose either an Adlerian approach (in this case, examining her family of origin) or Eye Movement Desensitization and Reprocessing (to deal with specific childhood traumas). She decided, however, that she wanted a therapy that allowed her to "stay in the present," and she made that therapy work for her.

In summation, our experience provided numerous examples supporting the notion that validating communities are a necessary component of self-stability (Ishiyama, 1995; Robertson, 2010). In this case, a validating community is considered to be a cultural group that supports the self-identity of the individual. Stability is achieved when that individual experiences a sense of temporal continuity in self-definition at a feeling level. The practice used here involved negotiating an understanding of the client's self in community, with therapy grounded in that negotiation. The therapy then served to validate the selves of the clients in question while concomitantly respecting the uniqueness of each individual.

\section{Discussion and Recommendations}

In this project, both international and native aboriginal students utilized culturally targeted counselling services, thereby helping to offset minority populations' underutilization of traditional on-campus services. By this measure, the project was successful, and we attribute this success to the availability of services in familiar settings and the flexibility with which counsellors adapted their methods to the internalized individual cultures of varied clientele. While this result supports the view that certain cross-cultural universals exist in counselling (Korhonen, 2002; Oulanova \& Moodley, 2010), it also supports the necessity of accommodating cultural differences through collaboration and negotiation (Collins \& Arthur, 2007). Both aboriginal and international students preferred making appointments directly with the counsellor instead of through an intermediary receptionist, and this preference may indicate a desire for a personal, empathetic relationship with the counsellor. Given that the role of professional counsellor is often not systemic to the cultures from which the target groups were drawn, it is natural that clients explored the client-counsellor relationship by attempting to define it in their own terms. Counsellors could expect a period of negotiation with respect to the nature of that relationship. An initial focus on academic issues, with the flexibility to deal with multiple concerns, allowed the counselling relationship to evolve.

An overriding principle gained from this experience is the importance of interagency cooperation and consultation. It is important to minimize the number of service providers a given client must see, and where multiple counsellors are needed, we recommend these counsellors work together collaboratively with their clients.

Although the historical and cultural backgrounds of aboriginal and international students are diverse, both need to draw on a sense of community while at university, and that need may be partially met through organizations like the Native Student Centre and the International Student Centre. It makes sense, therefore, to target services through such agencies. We would make the following suggestions to those offering such services: 
1. Counsellor visibility in both formal and informal settings should be maintained on an ongoing basis. This could include participation in social and educational events and orientation sessions, wherein the counsellor becomes identified as part of the community built around these students. For example, counsellors working with aboriginal populations could participate in cultural activities such as pipe ceremonies and traditional feasts.

2. Counsellors should allow for a certain degree of informality in accepting clients and in setting up client sessions. Many aboriginal and international students felt more comfortable dealing with a counsellor directly instead of going through a receptionist. Counsellors should be open to using a narrative style with clients who wish to tell their story in an oral tradition. This will normally mean some flexibility in the amount of time allowed for each session.

3. Counsellors should offer a series of skill-development workshops for international and aboriginal students. These workshops could become "talking circles" in which individual participants are invited to share their experiences and perceptions.

4. Groups of students may be encouraged to identify their formal and informal support networks away from home and to indicate how the role of the counsellor may fit into these support networks. Since counselling is not a service offered in many of the nations from which aboriginal and international students originate, and since the process of counselling may have cultural implications, it is suggested that groups of such students be invited to invent their own definition of counselling as it relates to their needs; the counsellor may facilitate this process using a community development approach, allowing clients to situate themselves in a collective framework with respect to family, community, and nation.

5. Counsellors should be willing to advocate for clients when such advocacy is necessitated by cultural and language barriers, or be willing to collaborate with student advisors who work to perform these tasks within their professional roles.

6. With client permission and respecting confidentiality, counsellors may work collaboratively with others involved in assisting the client in his or her change process. This may include active involvement with other agencies, both within the post-secondary institution and within the local community, that are engaging the client with respect to cognitive disabilities, psychiatric issues, and/or family needs. It may also involve collaborating with traditional elders, healers, or spiritual leaders within the client's community.

In summation, the practicum-counselling model used within universities prepares students for careers with traditional counselling agencies, but minority populations tend to underutilize such agencies. While cultural differences exist, and minority populations often emphasize cultural uniqueness in a process of self-identity construction (Robertson, 2011), many of the practices we recommend-such as seeking an understanding of the unique worldview of the individual, coupled with respecting principles of confidentiality and advocacy-are common to counselling practice generally. This finding supports the view of Korhonen (2002) that good multicultural counselling is simply good counselling. Heightening counsellor sensitivity to cultural differences, increasing accessibility to counselling services within minority cultural venues, and incorporating a community-development focus into counselling strategies will, in our opinion, assist in overcoming this 
disparity in service. The development of such skills needs to be included in educational programs. Practicums in multicultural counselling should recognize hours spent in crosscultural awareness and community-development activities. Counselling psychology is a demanding program, and it is our experience that without this kind of practical recognition, full-time students will not likely find the time for the extra work required to make counselling programs relevant to international and aboriginal students.

\section{References}

Adair, J. G. (2006). Creating indigenous psychologies: Insights from empirical social studies of the science of psychology. In U. Kim, K.-S. Yang, \& K.-K. Hwang (Eds.), Indigenous and cultural psychology: Understanding people in context (pp. 467-486). New York, NY: Springer Science.

Adler, A. (1967). Superiority and social interest: A collection of later writings. London, UK: Routledge and Kegan Paul.

Arthur, N. (2003). Preparing international students for re-entry transition. Canadian Journal of Counselling Psychology, 37(3), 173-185.

Arthur, N. (2004). Counselling international students. New York, NY: Plenum.

Atkinson, D. R., Poston, W. C., Furlong, M. J., \& Mercado, P. (1989). Ethnic group preferences for counselor characteristics. Journal of Counseling Psychology, 36(1), 68-72.

Bellini, J. (2003). Counselors' multicultural competencies and vocational rehabilitation outcomes in the context of counselor-client racial similarity and difference. Rehabilitation Counselors Bulletin, 46(3), 164-173.

Bennett, S. K., \& BigFoot-Sipes, D. S. (1991). American Indian and white college student preferences for counselor characteristics. Journal of Counseling Psychology, $38(4), 440-445$.

Brasfield, C. R. (2001). Residential school syndrome. B.C. Medical Journal, 43(2), $78-81$.

Collins, S., \& Arthur, N. (2007). A framework for enhancing multicultural competence. Canadian Journal of Counselling, 41(1), 31-49.

Dolan, C. A. (1995). A study of the mismatch between native students' counselling needs and available services. Canadian Journal of Counselling, 29(3), 234-243.

Duran, E., \& Duran, B. (1995). Native American postcolonial psychology. Albany, NY: State of New York Press.

Feuerstein, R., Hoffman, M., \& Rand, Y. (1979). The dynamic assessment of retarded performers: The learning potential device. Baltimore, MD: University Park Press.

Fowler, D. M., Glenwright, B. J., Bhatia, M., \& Drapeau, M. (2011). Counselling expectations of a sample of East Asian and Caucasian Canadian undergraduates in Canada. Canadian Journal of Counselling and Psychotherapy, 45(2), 151-167.

Haley, T. (2002). The fit between reflecting teams and a social constructionist approach. Journal of Systemic Therapies, 21(1), 20-40. 
Hare-Mustin, R. T., \& Marecek, J. (1997). Abnormal and clinical psychology: The politics of madness. In D. Fox \& I. Prilleltenski(Eds.), Critical psychology: An introduction (pp. 104-120). London, UK: Sage Publications.

Hersoug, A., Hoglend, P., Havik, O., \& Monsen, J. (2010). Development of working alliance over the course of psychotherapy. Psychology and Psychotherapy: Theory, Research and Practice, 83(2), 145-159. doi: 10.1348/147608309X471497

Ishiyama, F. I. (1995). Culturally dislocated clients: Self-validation issues and cultural conflict issues and counselling implications. Canadian Journal of Counselling, 29(3), 262-275.

Korhonen, M.-L. (2002). Inuit clients and the effective helper: An investigation of culturally sensitive counselling. Durham, UK: University of Durham.

McCormick, R. (1996). Culturally appropriate means and ends of counselling as described by the First Nations people of British Columbia. International Journal for the Advancement of Counselling, 18, 163-172.

Moody, R. (1999). Challenges and transformations: Counselling in a multicultural context. International Journal for the Advancement of Counselling, 21, 139-152.

Mosak, H. (1979). Adlerian psychotherapy. In R.Corsini(Ed.), Current psychotherapies (2nd ed., pp. 44-94). Itasca, IL: F. E. Peacock Publishers.

Oulanova, O., \& Moodley, R. (2010). Navigating two worlds: Experiences of counsellors who integrate aboriginal traditional healing practices. Canadian Journal of Counselling and Psychotherapy, 44(4), 346-362.

Poonwassie, A., \& Charter, A. (2001). An aboriginal worldview of helping: Empowering approaches. Canadian Journal of Counselling, 35(1), 63-73.

Ray, A. J. (1996). I have lived here since the world began: An illustrated history of Canada's native people. Toronto, Canada: Lester Publishing.

Robertson, L. H. (2006). The residential school experience: Syndrome or historic trauma. Pimatisiwin: A Journal of Aboriginal and Indigenous Community Health, 4(1), $1-28$.

Robertson, L. H. (2010). Mapping the self with units of culture. Psychology, 1(3), 185-193. doi: 10.4236/psych.2010.13025

Robertson, L. H. (2011). Prior learning assessment and recognition in aboriginal self (re) construction. Pimatisiwin: A Journal of Aboriginal and Indigenous Community Health, 9(2), 459-472.

Snider, P. D. (2001). Counselling for international students in western universities: A cross-cultural examination of counselling expectations and services. International Education Journal, 2(5), 61-85.

Sojonky, T. (2010). A self-study: Being a white psychologist in an Indian world. Bern, Switzerland: Peter Lang.

Stout, M. D., \& Kipling, G. (2003). Aboriginal people, resilience and the residential school legacy. Ottawa, Canada: Aboriginal Healing Foundation. 
Thomas, C. R., \& Marchant, W.C. (1993). Basic principles of Adlerian family counselling. In O. C. Christensen (Ed.), Adlerian family counselling (pp. 7-27). Minneapolis, MN: Educational Media Corporation.

Wesley-Esquimaux, C. C., \& Smolewski, M. (2004). Historic trauma and aboriginal healing. Ottawa, Canada: Aboriginal Healing Foundation.

White, M. (1993). The histories of the present. In S. G. Gilligan \& R. Price (Eds.), Therapeutic conversations (pp. 121-135). New York, NY: Norton.

\section{Contact Information}

Lloyd Hawkeye Robertson

Athabasca University

lloyd@hawkeyeassociates.ca

Lloyd Hawkeye Robertson is a registered psychologist in private practise in northern Saskatchewan, Canada and is on the faculty of Athabasca University. His research interests include self and identity in relation to mental health, residential school syndrome, prior learning assessment and recognition in relation to self-structure, and evolution in religious belief. He has supervised psychologists and other mental health professionals in northern settings and has provided workshops on counselling in aboriginal and northern communities.

Kathryn Holleran is currently a registered psychologist with the Dufferin-Peel Catholic District School Board in Mississauga, Ontario. She has provided psychological services to students in both post-secondary and secondary school settings.

Marilyn Samuels is currently Professor Emeritus in the Division of Applied Psychology, Faculty of Education at the University of Calgary. She was a registered psychologist and learning specialist in the Disability Resource Centre, where she supervised provisional psychologists and counselling students working in Student Services. She also provided psychology services to students with learning disabilities and other learning difficulties. 